\title{
Pentecostalismo de frontera y pentecostalismo de centro. Procesos de fronterización simbólica en el pentecostalismo altiplánico chileno-boliviano 1973-2007
}

\author{
Border and Center Pentecostalism. Symbolic \\ frontierization processes in the Chilean-Bolivian \\ highland pentecostalism 1973-2007
}

\author{
Miguel Ángel Mansilla ${ }^{1}$ http://orcid.org/0000-0001-5684-0787 \\ Sandra Leiva Gómez ${ }^{2}$ http://orcid.org/0000-0003-4883-6942 \\ Carlos Piñones Rivera ${ }^{3}$ http://orcid.org/0000-0002-4771-3345 \\ ${ }^{1}$ Doctor en Antropología. Instituto de Estudios Internacionales (INTE), Universidad Arturo \\ Prat, Iquique, CHILE. Email: mansilla.miguel@gmail.com \\ 2 Doctora en Sociología. Instituto de Estudios Internacionales (INTE), Universidad Arturo Prat, \\ Iquique, CHILE. Email: sandleiva@gmail.com \\ ${ }^{3}$ Doctor en Antropología. Instituto de Estudios Internacionales (INTE), Universidad Arturo \\ Prat, Iquique, CHILE. Email: carlospinonesrivera@gmail.com \\ Autor correspondiente.
}

\section{Resumen}

El artículo propone una lectura de la frontera como construcción social y cultural a través del concepto de fronterización simbólica. Para esto, analiza las representaciones y prácticas simbólicas que construye el pentecostalismo sobre lo fronterizo, mostrando los procesos que se dan entre el pentecostalismo de centro y de frontera, especificando lo que se propone en llamar una "altiplanización del pentecostalismo". La metodología consiste en la revisión sistemática de los números de la revista Fuego de Pentecostés entre los años 1973 y 2007, buscando analizar dichos procesos en la frontera chileno-boliviana. Se concluye sintetizando los rasgos principales de la fronterización simbólica y subrayando la necesidad de profundizar los estudios sobre estos procesos desde las metodologías basadas en la observación de los contextos contemporáneos.

Palabras claves: pentecostalismo, fronterización, frontera, altiplano, Chile, Bolivia.

\begin{abstract}
The article proposes a reading of the border as a social and cultural construction through the concept of symbolic frontierization. It analyzes the representations and symbolic practices that Pentecostalism constructs on the border, showing the processes that take place between center and border Pentecostalism and specifying what we call an "altiplanization of Pentecostalism". The methodology consists of the systematic review of the "Fuego de Pentecostés" magazine between 1973 and 2007, seeking to analyze such processes in the Chile-Bolivia border. It concludes by synthesizing the main features of this symbolic frontierization and emphasizing the need to deepen the studies on these processes from the methodologies based on the observation of the contemporary contexts.
\end{abstract}

Keywords: pentecostalism, frontier, border, altiplano, Chile, Bolivia.

Recibido: 20 septiembre 2017. Aceptado: 28 junio 2018 


\section{Introducción}

La Iglesia Evangélica Pentecostal (IEP) llegó al altiplano boliviano en el ańo 1938 de la mano del pastor Manuel González, su esposa e hijos. Comenzaron predicando en las plazas y calles de Cochabamba y después se trasladaron a predicar a Oruro, permaneciendo un total de 8 años en Bolivia. En el año 1945 se convirtió al pentecostalismo el boliviano Daniel Salguero y en 1948 fue ordenado como el primer pastor boliviano de la IEP, en la ciudad de La Paz. Mientras potenciaba el liderazgo local, el pentecostalismo seguía enviando misioneros chilenos. Por ejemplo, en 1957 llega a Cochabamba un misionero de nombre Manuel Vera, junto a su esposa y cinco hijos, quien permaneció 8 años en Bolivia. En 1958 es enviado el pastor Carlos Rodríguez a Oruro, junto a su esposa y dos hijos, y permaneció 11 ańos en Bolivia (Fuego de Pentecostés, núm. 763, pp. 12-13, 1993).

Pese al envío de misioneros del centro de Chile al altiplano boliviano, ${ }^{1}$ serán los líderes indígenas (aymaras, quechuas o chipayas), tanto bolivianos como chilenos, quienes harán crecer el pentecostalismo en Bolivia. Tal es el caso del pastor Braulio Mamani, quien comenzó a predicar en lengua aymara en Cariquima (Chile) y llegó hasta Sabaya (Bolivia) en 1958. Del mismo modo, Eustaquio Ayaraviri predicará en aymara y quechua. Otro importante líder indígena será Norberto Vilca (Fuego de Pentecostés, núm. 616, pp. 11-12, 1980). La IEP sin el liderazgo indígena, fundamentalmente aymara, hubiese desaparecido en Bolivia. Durante los primeros 30 años su crecimiento fue muy lento, pero se fue acelerando a partir de la década del setenta con la asunción del liderazgo indígena local. Se produce entonces el crecimiento y expansión geográfica que le es característico y que le permitió en el año 1993 alcanzar unas 47 iglesias establecidas a lo largo de la frontera oriente de Bolivia (Fuego de Pentecostés, núm. 763, p. 13, 1993). El pastor Braulio Mamani destacó que solamente él había levantado "más de 40 locales [iglesias pequeñas] en estas fronteras en 12 años de trabajo" (Fuego de Pentecostés, núm. 609, p. 13, 1980). Para el año 2007 la IEP ya contaba con más de un centenar de iglesias en Bolivia. No obstante,

1 El pentecostalismo se funda en Chile, en Valparaíso, el año 1909 (Mansilla, 2014). continuaba con las mismas prácticas chilenizadoras, centralistas y extractoras de los diezmos de Bolivia a Chile, motivo por el cual se produce en ese año el cisma entre la Iglesia evangélica pentecostal chilena y la boliviana.

La religión se constituye en un importante marcador y diferenciador de espacios fronterizos; dado que la frontera es un constructo conceptual particular que la gente imprime algunas veces en el mundo, por cuanto "trazar una frontera es un acto cognitivo" (Barth, 2000, p. 19, citado en Del Cairo, 2003, p. 105). La religión afecta y es afectada en la frontera (Rivera, 2014). En primer lugar, sigue lineamientos, profundizándolos en una dimensión simbólica, al considerar las fronteras como espacios opuestos y vacíos (Paniagua, 2002; Rivera, 2014) y, en segundo lugar, reproduce eternas disputas entre el centro y la frontera como lo sagrado y lo profano, cosmos y caos, vida y nada (Eliade, 1981).

Tradicionalmente las investigaciones abordaron el proceso de fronterización como un territorio político administrativo que separa dos o más naciones. Pero hoy por hoy la frontera ha adquirido relevancia como una construcción social (Tapia, 2012; Tapia y González, 2014), aludiendo a la idea de un espacio heterogéneo, descentrado y dinámico (Del Cairo, 2003; Botero, 2008; Solís y Martínez, 2012) y por último como una construcción cultural (Barth, 2000; Giménez, 2000; Núñez et al., 2013). Sin embargo, desde lo cultural se ha desatendido la dimensión simbólica del proceso de fronterización. Los geógrafos le han prestado últimamente atención a la dimensión simbólica del territorio (Giménez, 2000; Núnez et al., 2013), afirmando que "el territorio puede ser apropiado subjetivamente como objeto de representación y de apego afectivo, y sobre todo, como símbolo de pertenencia socioterritorial" (Giménez, 2000, p. 29). Siguiendo a Giménez, quien señala que "todo territorio implica tres aspectos: la apropiación de un espacio, el poder y la frontera" (Giménez, 2000, p. 22), reconocemos que una frontera no es solo geográfica, sino también cultural, generándose por consiguiente "apropiaciones simbólicas expresivas del espacio” (Ibíd., p. 30).

Nuestro propósito es, por lo tanto, enfocarnos en las representaciones simbólicas del espacio que 
construye el pentecostalismo sobre lo fronterizo. Esta concepción simbólica del espacio la tomaremos de Mircea Eliade (1981). Desde esta perspectiva, la frontera se constituye en un espacio en permanente control desde el centro. ¿Pero qué sucede cuando la frontera adquiere relevancia y se constituye en uno de disputa simbólica? ¿Qué sucede cuando es la frontera la que comienza a afectar al centro? ¿Cuáles son las relaciones que construyen el centro y la frontera, es decir, el pentecostalismo de centro y el pentecostalismo de frontera? Estas son algunas de las preguntas que el presente texto se propone responder.

Por otra parte, las investigaciones referidas al pentecostalismo en Bolivia han sido diversas (Wagner, 1970; Albó, 1988; Rivière, 1988, 2004; StröbeleGregor, 1989). Sin embargo, el único autor que se ha preocupado por investigar la importancia del pentecostalismo en Bolivia y su importancia como religión fronteriza indígena ha sido Rivière (1988, 2004).

La presente investigación quiere ir más allá, analizando los procesos de fronterización simbólica que estableció el pentecostalismo, entendiendo por procesos de fronterización simbólica aquellas "imágenes, formas discursivas, acciones, pensamientos, $y$ sentimientos, que son una barrera imaginaria levantada en torno a los otros" (Paniagua, 2002, p. 144). La frontera chileno-boliviana, en donde están asentados los aymaras, y en menor medida los quechuas, comparten historias comunes, tales como procesos de posguerras; políticas de desindigenización a través de distintas instancias nacionalistas y estatales; territorios invadidos por centros industriales, y sumado a ello la estigmatización del indígena. Además, por el lado chileno, el aymara fue permanentemente confundido con el boliviano, por lo tanto, sospechoso de ser el enemigo. ${ }^{2}$

2 Nos referimos a que durante el período de la dictadura militar de Chile (1973-1989) la figura del enemigo "peruano" y "boliviano", imaginario heredado de la Guerra del Pacífico, fue revitalizada por la dictadura y por tanto la frontera fue protegida con minas antipersonales, para desincentivar una posible invasión por los pasos no habilitados. Por eso el boliviano cargaba un doble estigma: indio y enemigo.
El objetivo de este artículo es analizar los procesos de fronterización simbólica que se dan entre el pentecostalismo de centro y el de frontera. Para ello nos enfocaremos en el análisis de la relación que se produce en el pentecostalismo chileno y boliviano del altiplano en torno a ciertos elementos culturales indígenas aymaras y quechuas, en oposición al pentecostalismo de centro. Tales elementos originan lo que podríamos llamar un pentecostalismo fronterizo, estableciendo características singulares que lo diferencian ampliamente del pentecostalismo de centro. En este sentido planteamos en este artículo la tesis de que el pentecostalismo fronterizo se torna un concepto unificador y diferenciador a la vez, configurando lo que hemos denominado aquí como una altiplanización del pentecostalismo.

Este artículo lo hemos dividido en seis apartados. En primer lugar, escribimos una sección metodológica para situar el contexto discursivo de donde extrajimos la información analizada. Esta proviene de la revista Fuego de Pentecostés (RFP), perteneciente a la Iglesia Evangélica Pentecostal (IEP). Se trata de una publicación que siempre ha estado en el centro de Chile, de donde es originario el pentecostalismo chileno. La RFP nació en Concepción (en el corpus aludimos a los cambios de nombre que ha sufrido), luego fue trasladada a Valparaíso y finalmente a Santiago. Esta revista ha estado dirigida por los Superintendentes (jefes máximos de la IEP), quienes igualmente siempre han sido del centro, en consecuencia, la RFP es una revista que transmite e institucionaliza un discurso ideológico del pentecostalismo céntrico.

Luego continuamos con los liderazgos de fronteras: tensión entre el centro y la frontera chilenoboliviana. Aquí destacamos que el crecimiento del pentecostalismo en esa frontera se debió a la acción desenvuelta de los líderes de frontera, especialmente aymaras y quechuas, quienes luego fueron desplazados, invisibilizados y menguados en la reinvención de los mitos fundacionales de la institución.

En un tercer apartado nos referimos a los templos de frontera, en donde destacamos que la preocupación de los líderes fronterizos no estaba focalizada en construir templos sino casas-templos; algo que los conecta con la memoria cultural del sentido 
comunitario de lo religioso. La ideología religiosa céntrica presionaba en la construcción de templos, de modo de tener el control y la administración y así disponer de liderazgo para trasladar a los líderes indígenas locales a otros lugares con el fin de evitar conflictos entre frontera y centro, algo que irremediablemente sucedió posteriormente, cuando en el año 2007 se produce el cisma que da origen a la IEP boliviana y la IEP chilena en Bolivia.

Posteriormente nos referimos a la metaforización de las fronteras. El pentecostalismo de frontera comenzó a tener visibilidad por su insospechado crecimiento gracias a la alta conversión de indígenas, en una magnitud que no había experimentado el pentecostalismo chileno. Entonces la frontera adquiere relevancia y visibilidad y comienza un proceso de centrificación, mientras el pentecostalismo de centro empieza a fronterizarse. De este modo la ideología céntrica pentecostal da inicio a un proceso de reinvención de los mitos fundacionales poniendo el crecimiento fronterizo como una acción orquestada y planificada desde el centro, para lo cual utiliza distintas metáforas: agrícolas, marciales, fanales, supranacionales y metanacionales como una forma de disminuir la acción fronteriza.

En la quinta sección destacamos que lo que permitió el crecimiento pentecostal, visible en la década del ochenta, fue el liderazgo indígena, la inclusión de las mujeres (especialmente las esposas de los líderes) y el uso de las casas-templos. No obstante, lo que hizo efectiva la conversión fue la aplicación de los capitales culturales, sociales y simbólicos propios de la cultura altiplánica, por parte de los líderes indígenas. Esto fue lo que permitió al pentecostalismo de origen chileno transformarse en un pentecostalismo altiplánico.

Finalmente, el sexto apartado analiza el uso de las lenguas indígenas como frontera simbólica. La utilización de las lenguas indígenas permitió a los líderes interpretar los símbolos y metáforas bíblicas agrícolas, rurales y campesinas y transmitirlas a los indígenas en su lengua vernácula. De este modo el lenguaje religioso pentecostal se tornó pertinente en una cultura indígena, algo que los líderes del centro, que inicialmente se instalaron en estos espacios indígenas, nunca lograron.

\section{Aproximaciones metodológicas}

La información que analizamos la extrajimos de la revista Fuego de Pentecostés (RFP), de la Iglesia Evangélica Pentecostal (IEP). En sus inicios, esta revista tuvo otros nombres: revista Chile Evangélico (1909-1910), Chile Pentecostal (1910-1927) y, por último, Fuego de Pentecostés (1928-actualidad), conformando todas una publicación continuada. La revista Chile Evangélico nació en Concepción, el 11 de septiembre de 1909, perteneciente a la Iglesia Presbiteriana de Concepción. Esta publicación difundió las noticias del avivamiento pentecostal de 1909, que entregaban los propios involucrados en el avivamiento (derramamiento del Espíritu Santo), y se caracterizó por incluir testimonios y relatos del lego no pastoral, como era habitual en la revista $E l$ Cristiano de la Iglesia Metodista Episcopal, algo que el pentecostalismo heredará. El 24 de noviembre de 1910 es traspasada al movimiento pentecostal y pasa a llamarse Chile Pentecostal. Se publica en Concepción hasta el año 1915; más tarde es editada en Valparaíso bajo la dirección y redacción de Willis Hoover, y a contar de la década del cincuenta se traslada a Santiago. La forma de distribución es a través de las mismas iglesias: los creyentes las encargaban a sus pastores y estas llegaban a los templos donde eran adquiridas por los fieles. Era tanto una forma de generar institucionalización como un espacio para que los creyentes contaran sus testimonios y rompieran el anonimato. El pentecostalismo chileno nació como una religión del centro, asume así la ideología del centro y con una visión concéntrica la extiende hacia las regiones, hacia los márgenes y las fronteras culturales.

Para este estudio usamos como fuente documental la revista Fuego de Pentecostés porque: a) es la única revista de la denominación religiosa; b) es la única denominación pentecostal de origen chileno existente en el altiplano boliviano; c) es la única fuente de información pentecostal escrita que brinda información sobre el problema de investigación y lo hace de una forma abundante. La IEP es el único centro religioso evangélico chileno relevante en el altiplano boliviano. Encontramos otros como los adventistas en el altiplano peruano que en menor medida se conecta con La Paz (Bolivia), es de origen norteamericano y ha sido relevante en el plano de 
la educación intercultural. En el caso del altiplano boliviano también encontramos a los metodistas, pero con una relevancia mínima. Por tanto la IEP es la denominación evangélica chilena que transita entre el altiplano chileno y boliviano, entre fronteras étnicas, mediada por lo nacional y en la que se conjugan las fronteras religiosas con lo andino (aymara y quechua).

Iniciamos el análisis de la información en 1973, año en que la IEP obtiene su personalidad jurídica en el territorio boliviano, y lo extendemos hasta 2007, cuando se produce el cisma de la IEP entre Chile y Bolivia. Se revisan por tanto los relatos y testimonios de un lapso de 34 años, que corresponde a un total de 408 números de la revista. Del cúmulo de información solo nos centramos en todo aquello concerniente a Bolivia. Entre 1973 y 1979 las noticias fueron pocas, sin embargo, a contar del año 1980 comienzan a aumentar. Dejamos de lado los encuentros y reuniones eclesiásticas dado que solo se concentraban en los nombres de pastores y representantes que asistían. Finalmente, recopilamos la información que nos pareció antropológicamente relevante y, dado el espacio limitado con que contábamos, nos quedamos solamente con lo esencial de los párrafos.

En este artículo hemos acuñado tres conceptos centrales: pentecostalismo de centro; pentecostalismo de frontera y altiplanización del pentecostalismo.

a) El pentecostalismo de centro. Nos referimos al carácter patriarcal, centralista, urbano y civilizador que adquirió el pentecostalismo en la medida que se fue extendiendo hacia las regiones y especialmente hacia aquellos grupos religiosos distintos culturalmente, como los indígenas, en este caso los aymaras. Aquí los pentecostales controlaron el uso de la lengua, las indumentarias indígenas, los espacios sagrados ancestrales y la segmentación de la cultura;

b) El pentecostalismo de frontera. Nos referimos al carácter dinámico e imprevisto de la conversión, como toda acción humana, en el sentido de que si bien la institucionalización del pentecostalismo intenta generar una homogeneización de las formas y contenidos de las creencias, prácticas, ritos y mitos, el pentecostalismo de frontera generó su diferenciación, influido por los contextos culturales, históricos y geográficos específicos. De este modo se produjo una lucha de representaciones e imaginarios entre el centro y la frontera, no obstante, es esta lucha la que genera que el pentecostalismo crezca en las fronteras. En todo caso, los mismos centros tienen sus fronteras, así como las mismas fronteras tienen sus centros, lo que evita las polaridades infranqueables.

c) Altiplanización del pentecostalismo. Cuando el pentecostalismo de centro llegó primero al altiplano boliviano y luego al chileno, intentó realizar una homogeneización. Sin embargo, dado que los líderes religiosos más efectivos fueron los líderes aymaras y quechuas, quienes generalmente predicaban y cantaban en el idioma vernáculo, se produjo un pentecostalismo distinto del centro. Este pentecostalismo se "aymariza" o "quechuiza" según el grupo étnico donde se desarrolle. La lengua, los ancestros, los ritos, los mitos y los espacios de culto ancestrales altiplánicos adquieren valor y son redefinidos e incluidos en el pentecostalismo, produciéndose de este modo una altiplanización de este. ${ }^{3}$

\section{Los liderazgos de fronteras: tensión entre el centro y la frontera chileno-boliviana}

El pentecostalismo de frontera produce una redefinición del mito fundacional que, aunque nació como un trabajo del pentecostalismo de centro, al no tener resultados por 30 ańos motiva la aparición de líderes locales, quienes comienzan a ganar conversos y crear casas-templos y templos en distintos lugares del altiplano. Pero no se trató de un fenómeno planificado de la frontera, sino espontáneo. El trabajo religioso realizado por líderes indígenas, pionero de su comunidad en cuanto a conversión, en la frontera chileno-boliviana hizo posible el establecimiento del pentecostalismo en el altiplano boliviano y chileno, pues las dificultades eran muchas: territorios inhóspitos, climas extremos, puna,

3 Utilizamos el concepto de altiplanización del pentecostalismo por sobre otro gran concepto como hibridez cultural, ya que este último alude al encuentro entre lo moderno y lo tradicional. La relación entre pentecostalismo y cultura andina no es una relación modernotradicional, sino más bien tradicional-tradicional, de ahí que se trate de una mutua permeación. 
ausencia de transporte, comunidades indígenas que desconocían el español y personas adultas que no sabían leer. Mientras algunos autores vieron en las misiones pentecostales una desaymarización, otros como Xavier Albó apuntaron que "los aymaras pentecostales no dejan de sentirse aymaras, sino que se blanquean" (Albó, 2003, p. 119). Este proceso coexistente de valores, costumbres y creencias permitió, por una parte, a los aymaras encontrar posibilidades para enfrentar la estigmatización, y por otra, al pentecostalismo arraigarse en territorio aymara.

Uno de estos líderes fue el pastor Braulio Mamani, aymara, cuya labor religiosa inicial la realizó de manera independiente de la Iglesia Evangélica Pentecostal (IEP). ${ }^{4}$ No obstante, años más tarde su trabajo será institucionalizado, atribuyéndosele un origen centralista y chilenizador. Para fundamentar esta postura la IEP subraya que el trabajo misionero de Mamani en la frontera chileno-boliviana fue revelado por Dios a la IEP en Santiago, en donde "un hermano tuvo un sueño. Una bola ardiendo se levantó en Santiago de Chile y fue a caer a Cariquima y rebotó y fue caer a Pisiga, Coipasa, Sabaya (Bolivia) y siguió incendiando las fronteras todo a su paso más al norte" (Fuego de Pentecostés, núm. 763, p. 12, 1993) (Figura 1).

Treinta años más tarde se interpreta un trabajo religioso fronterizo como originario del centro, para integrarlo a una práctica misional institucional, representándolo con la metáfora ígnea aludida arriba. A la IEP le interesaba establecer claras fronteras entre lo chileno y lo boliviano, lo individual y lo institucional, lo indígena y lo mestizo. Pero, por sobre todo, se trataba de una lucha simbólica entre la frontera chileno-boliviana y el centro, entendiendo que la frontera "permite cruces y contactos, tránsitos de diversos elementos" (Solís y Martínez, 2012, p. 10): la frontera se caracteriza por su heterogeneidad, sin embargo es concebida desde el centro como homogénea e irrelevante. Por el contrario, el centro es imaginado como el espacio donde "ocurre lo sagrado real por excelencia, y a la vez la potencia y la eficiencia de la vida y la

4 Braulio Mamani se convirtió al pentecostalismo (a la IEP) en Diego de Almagro (región de Atacama) en el ańo 1957 y una vez terminado su servicio militar, regresa a Colchane a predicar, teniendo únicamente vínculos con el pastor Marcial Flores de Iquique, pero no con Santiago. fecundidad" (Eliade, 1981, p. 8). Desde la década del setenta la dinámica del pentecostalismo se sitúa en la frontera, lo que "implica tanto a un centro como a una periferia, intersticial en la que es posible localizar elementos heterogéneos y descentrados" (Solís y Martínez, 2012, p. 10) y por ello desde el centro se hizo necesario realizar demarcaciones culturales claras.

En esta tensión entre el pentecostalismo de frontera y el pentecostalismo del centro la frontera se concibe como "la revelación de un espacio sagrado que permite obtener un punto fijo, orientarse en la homogeneidad caótica y transformarse en un espacio sagrado relevante" (Eliade, 1981, p. 7). En vista de ello el crecimiento del pentecostalismo en la frontera es interpretado con un énfasis céntrico (y además chilenizador): "Algo muy conmovedor fue ver a pastores y hermanos de las fronteras, al oír hablar al sencillo y humilde siervo de Dios, el pastor Braulio Mamani Amaro; a quien Dios utilizó como antorcha encendida" ("Misión a la amada Bolivia", 1985, p. 12). El pastor Mamani es presentado y resaltado a un nivel heroico por la IEP, en desmedro de líderes bolivianos como el pastor Norberto Vilca, no solo porque "en las zonas fronterizas se genera comunicación y tensión entre procesos plurirreligiosos y seculares" (Solís y Martínez, 2012, p. 10), sino porque el centro lucha por el control y dominio simbólico. En este proceso el pentecostalismo utiliza símbolos que refundan su accionar en la frontera chileno-boliviana. Se vale así de metáforas candiles para concebir la cultura indígena, antes de su llegada, como tiempos y espacios en oscuridad, en donde el pastor Mamani es la "antorcha encendida". Un territorio es vacío y desierto si no lo han ocupado los "nuestros", "al ocuparlo y, sobre todo, al instalarse en él, 'lo nuestro' lo transforma simbólicamente en un cosmos [espacio ordenado] por un espacio ritual de la cosmogonía” (Eliade, 1981, p. 9). Para los pentecostales chilenos Braulio Mamani es más "nuestro" que un líder pentecostal boliviano y por ello se le destaca como "sencillo y humilde siervo de Dios". No obstante su éxito como predicador de frontera, nunca fue ascendido ni reconocido más allá de pastor. ${ }^{5}$ Esta falta de reconocimiento ocurre

5 Cuestión que contrasta con la historia del pastor Manuel González, quien con menos éxito en Bolivia llegó a ser pastor presidente nacional de la IEP en Chile entre 1961 y 1984. 


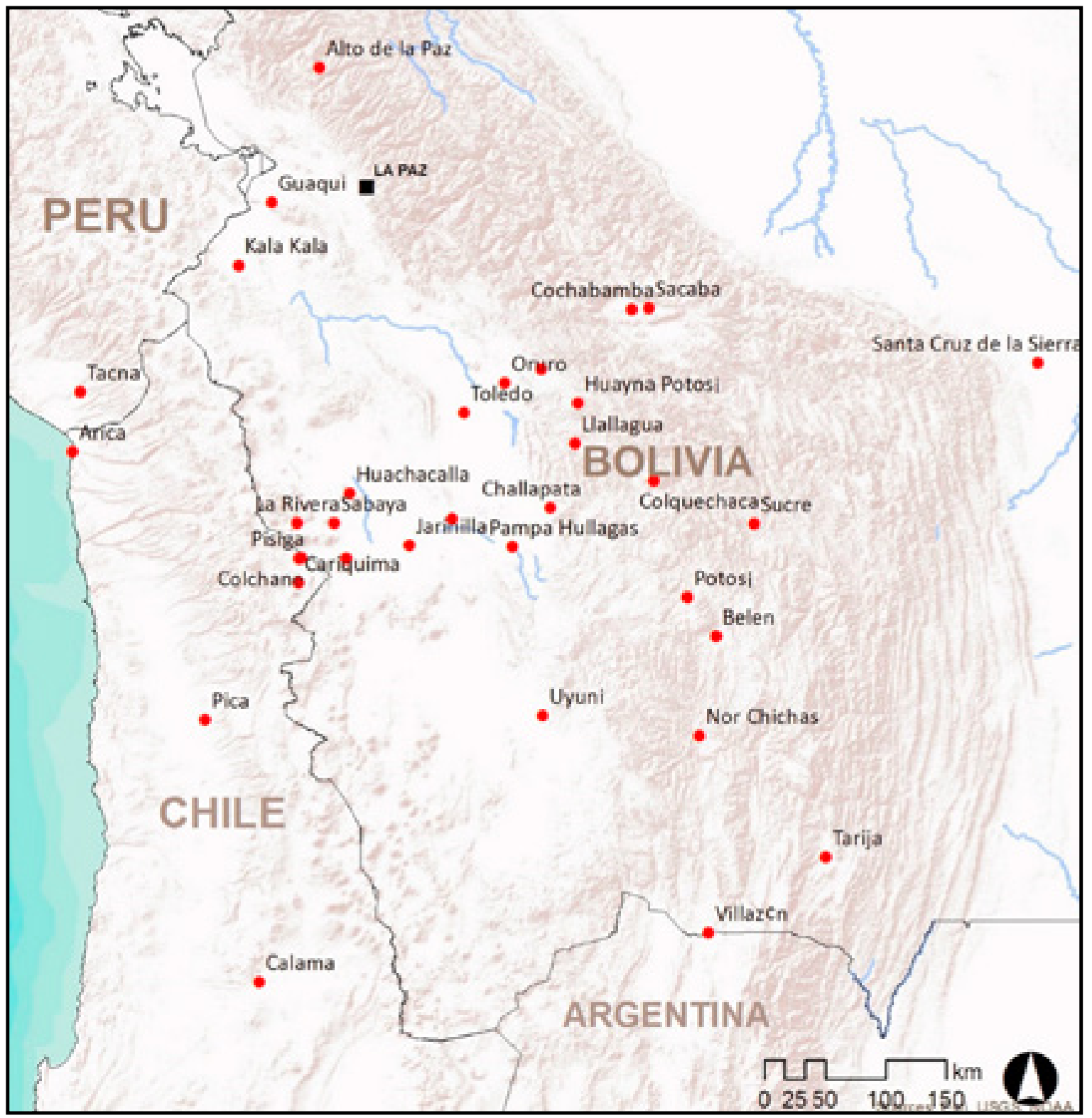

Figura 1. El pentecostalismo altiplánico chileno-boliviano 1973-2007. Fuente: Elaboración propia.

porque la religión reproduce las fronteras simbólicas de la cultura nacional, en donde líderes indígenas y líderes regionales no alcanzan liderazgos de importancia nacional.

Braulio Mamani es concebido como un axis mundo, "un hombre santo", una compensación simbólica frente a la ausencia de reconocimiento organizacional. Pero sigue siendo un líder fronterizo, no del centro. Es "el hombre que atravesó la frontera [chi- leno-boliviana] predicando por las aldeas, sanando enfermos, echando fuera demonios, pedaleando en su bicicleta y llevando a su esposa, durmiendo en las quebradas o en el desierto frío, revestido de poder de Dios; sin sabiduría, un pobre hombrecito, como se dice él mismo" ("Misión a la amada Bolivia”, 1985, p. 12). El territorio fronterizo, desde la perspectiva religiosa, es representado como un espacio vacío y sin vida, caótico y demoniaco, pero una vez ocupado se transforma en "un umbral y a la vez un hito, la 
frontera que distingue y opone dos mundos y el lugar paradójico donde dichos mundos se comunican y se puede efectuar el tránsito del mundo profano al mundo sagrado" (Eliade, 1981, p. 7).

En síntesis, el pentecostalismo llegó al altiplano boliviano el año 1938. Su crecimiento fue muy lento, pero con la conversión de Braulio Mamani en el año 1957 y luego con Norberto Vilca en 1964, comenzó a extenderse por todo el altiplano de la frontera chileno-boliviana. No obstante, esto pasa inadvertido hasta la década del ochenta, cuando el pentecostalismo del centro irrumpió en estos espacios con distintas visitas de altos dignatarios de la IEP de Santiago, así como congregando hermanos en los espacios altiplánicos y además invitando a los líderes fronterizos para que controlasen los sucesos en sus confines. Se reinventan distintas metáforas, sobre todo aquellas referidas a los líderes fronterizos, los cuales son representados como puertas elegidas por el centro para estar en la frontera. Por consiguiente, la existencia del espacio y del liderazgo es un producto del centro. En estas reuniones el crecimiento altiplánico es reinventado y presentado como una orquestación del centro, cuyo trabajo había sido revelado a los líderes del centro, pero mantenida oculta porque no entendían el significado del símbolo ígneo y espacios revelados, hasta que la claridad del vaticinio llegó en la década del ochenta.

\section{La importancia de los templos en el pentecostalismo de frontera}

La diferenciación que el centro establece y transmite es que la frontera es ontológicamente insuficiente, por consiguiente, no hay que invertir para construir templos suntuosos que opaquen el centro. De este modo se configura esta inevitable oposición: el centro es catedralicio y cardenalicio, en cambio la frontera es de capillas y pastores-obreros. Si por algún motivo el líder fronterizo comienza a adquirir relevancia, entonces es trasladado o asignado a cargos menores en organizaciones céntricas, para impedir que se constituya en sujeto cardenalicio y luego construya templos-catedrales, atrayéndole importancia inusitada a la frontera, situación que el centro concebía como una amenaza.
En los distintos relatos se muestran los constantes itinerarios de visitas fronterizas que realizaban los pentecostales chilenos y bolivianos, constituyendo iglesias como puntos de encuentro para fortalecer su presencia en un territorio considerado deshabitado.

[E]n Coipasa nos recibe el hermano Francisco Manuel y congregación [...] llegó el pastor Juan Colqui, de Sabaya [...] viajamos a Huachacalla para tener reunión con los hermanos de este lugar; su gran templo está lleno de almas [...] llegamos a Anco-Kala [...] En Oruro: Pablito Mamani nos fue a encontrar más allá de Anco-Kala [...] Challapata; aquí está el hermano Nazario Sánchez, con muchos hermanos de su iglesia que nos reciben cantando [...] volvimos Oruro, y luego de vuelta a Chile, todo el día por las fronteras para llegar de noche a Cariquima y de ahí a Iquique ("Misión a la amada Bolivia", 1985, p. 12).

Desde siempre los templos han sido considerados "puertas del cielo", un imago mundi, la reproducción terrestre de un modelo trascendente. Por ello iglesia y templo son percibidos como distintivos. Si el templo es imago mundi, la iglesia se entiende como el axis mundi. Empero, un templo es también una frontera simbólica entre lo sagrado y lo profano, en donde se evoca y "convoca a sujetos interactuando entre actores o grupos, recreada y generada cada vez que se actualiza y se realiza la relación interactiva" (Solís y Martínez, 2012, p. 11).

Otro relato muestra un itinerario similar:

Recibimos en Tarija, la visita de nuestro Pastor de Zona. El 17 de abril salió de su Iglesia a Colquechaca; de allí lo acompañó el Pastor Alberto Castro, hasta llegar a la Iglesia de Tola Palca. De allí viajaron con el Pastor Castro hasta llegar a la Iglesia de Potosí. El Pastor Florentino Ramírez, viaja a la Iglesia de Tarija. De ahí a la Iglesia de Villazón, donde se encuentra el Pastor Hayler Calle. El lunes 27 de abril llegamos a la Iglesia de Challapata. El 29 de abril, viajamos a la iglesia de Ucumasi con el Pastor Juan Estanislao 
Copa. Llegamos a la Iglesia de Jarinilla; en el trayecto observamos la naturaleza del río Laca Jahuira que pasa por el lado del pueblo Pampa Hullagas, Belén hasta desembocar a la Laguna de Coipasa [...] Así llegamos por la tarde a la Iglesia de Jarenilla, pasando el río en botecito... Viernes $1^{\circ}$ de mayo seguimos viajando en bicicleta todo el día con dirección a un local de la Iglesia de Ucumasi, llamado Calavillca, por la tarde atravesamos un gran arenal, donde nuestros pies se hundían y se agotaban las fuerzas ("Viaje Misionero al sur de Bolivia”, 1988, p. 10).

La narración muestra el itinerario de templos de la IEP en Bolivia en las pequeñas ciudades de Oruro, para terminar en Cochabamba, los que son importantes porque "el templo re-santifica continuamente el Mundo que lo representa y al propio tiempo lo contiene" (Eliade, 1981, p. 17). Los templos fronterizos siempre deben ser menores, más pequeños que los del centro, pues estos últimos son considerados siempre el ombligo del mundo, es "la tierra santa, el lugar más próximo al cielo, porque desde aquí, desde nuestro país, se puede alcanzar el cielo: nuestro mundo, según eso, es un lugar alto" (Ibíd., p. 11). En el centro se pretende que esté la imagen y en la frontera solo se dé la semejanza. Pero las fronteras se niegan a este proceso de pasividad y reduccionismo, limitado históricamente a un imaginario espacial de colisión y disputa, sino que se yerguen como espacios de vida.

Como destaca Botero, las fronteras "se constituyen como una zona de atracción, de refugio y de rechazo, actuando al fin como crisol social" (Botero, 2008, p. 10). Esto se observa en las iglesias fronterizas: "el 13 de abril de 1997, en Nor Chichas ${ }^{6}$ selvática, se celebra la ceremonia de inauguración de un nuevo templo... por el Pastor Alfonso Colque Mamani dueño de casa... [y] el Pastor Modesto Zarzuri de la Iglesia en Tacna-Perú... vecinos de esta localidad en esta tierra de los étnicos; chimanes y mosetenes..." ("Inauguración de un nuevo templo de la Iglesia en Caranavi La Paz-Bolivia”, 1997, p. 10). Se trata de pueblos pertenecientes a Potosí. Aparecen en el re-

6 Nor Chichas es una provincia de Bolivia en el sudeste del Departamento Potosí. lato otras etnias como chimanes y mosetenes, pero no se destaca la práctica de culto en sus lenguas. En este imaginario el pentecostalismo se está presentando como espacio multiétnico. Consiguientemente, el templo es un punto fuerte en el que se expresan "imágenes de rupturas: allí, en el recinto sagrado, en donde se hace posible la comunicación con las divinidades: por consiguiente, debe existir una puerta [templo] hacia lo alto por la que las divinidades puedan descender a la tierra y las personas puedan subir simbólicamente al cielo" (Eliade, 1981, p. 7).

A los templos pentecostales fronterizos se les infiere como aberturas a lo sagrado real. Son puertas abiertas, escaleras para comunicarse con lo verdaderamente divino. En este sentido, se destaca a "Guaqui: En el Alto de la Paz, en las fronteras con el Perú, está el esforzado obrero, Demetrio Sánchez y su pequeña Iglesia construyeron su Capillita en este pueblo [...] Se reúnen peruanos y bolivianos en esta casa de oración" ("Noticias de la iglesia en Bolivia consagración de cuatro templos", 1987, p. 18). Una importante característica de lo fronterizo es su diversidad, pese a su invisibilidad. En el espacio fronterizo se aprecia cooperación y confianza para reunirse y construir así un templo nuevo, el que será guiado por un extranjero. Este espacio constituye un umbral, "es la solución de continuidad con el espacio: de ahí su gran importancia religiosa, pues es a la vez símbolo y vehículo de tránsito" (Eliade, 1981, p. 7). Ejemplos de encuentro de diversas nacionalidades en los espacios fronterizos se aprecian también en otras localidades: "en la Ciudad de Sucre, se reunieron 125 jóvenes provenientes de 22 Iglesias de Bolivia, así como la participación de una delegación de Chile y una del Perú, para un encuentro espiritual. Nos honraron [...] los Pastores Eloy Yave, Jacinto Marca, Isaías Ayaviri, Andrés González y nuestro Pastor anfitrión Alberto Castro" (Fuego de Pentecostés, núm. 924, p. 7). Las fronteras religiosas se constituyen así en espacios "productivos de nuevas identidades y etnicidades" (Botero, 2008, p. 10). Aun cuando entre las fronteras y el centro existan claras distinciones y diferencias, el centro siempre propenderá a ejercer su poder simbólico para modelar esas identidades a su imagen y semejanza.

Se muestra un pentecostalismo fronterizo "como un espacio hierofánico, de irrupción de lo sagrado 
que tiene por objeto destacar un territorio del medio cósmico circundante y hacerlo cualitativamente diferente" (Eliade, 1981, p. 7) del pentecostalismo del centro. La frontera se constituye en un espacio de evocación, invocación y de conjuración: “...consagramos una casa de Dios en Pampa Mogachi, ubicada a $26 \mathrm{~km}$ de la frontera Chile-Bolivia. El acto fue presidido por el Pastor Florencio Moya. También nos honraron con su presencia nuestro Pastor Juan Colque, y otros Pastores, y con la presencia de autoridades locales" ("Consagración de Templos Centrales en Bolivia. Huanuni”, 1998, p. 16). Pampa Mogachi es una localidad que está a 3900 msnm, fronteriza con Chile. Como destaca Brenna, "la frontera ha sido siempre un referente en el que se enfrentan las identidades, los nombres, los símbolos, los imaginarios diferenciados" (Brena, 2011, p. 9). En este sentido la frontera se constituye como un espacio en disputa y apropiación simbólica, pero también de negociación y contribución simbólica. En "Todo Santo, local de la Iglesia en La Rivera, a pocos metros del Hito Boliviano chileno Chinchillane se inauguró la ampliación y remodelación de un templo de 5x16 mts" "“Consagración del Templo en Todo Santo-La Rivera”, 2004, p. 2). Aquí también encontramos una localidad en la frontera, La Rivera, ubicada en la provincia de Mejillones (Bolivia), donde permanentemente se dan relaciones fronterizas con intercambios de actividades religiosas entre creyentes pentecostales bolivianos y chilenos.

De esta forma los templos pentecostales fronterizos se constituyen en espacios intermedios, de refugio e interludiales. Son lugares santos, lugares altos y puntos fijos, la frontera se vuelve entonces importante. Por ello la inauguración se realiza con relevancia política al invitar a las autoridades locales: "Inauguración del nuevo Templo en San José de Kala, frontera con Chile... presidido por nuestro Pastor Juan Colque Ayma. También nos honraron con su visita el Pastor René Rivero de la Iglesia en Pisiga, Bolivia” ("Consagración del Nuevo templo en San José de Kala- Bolivia”, 2005, p. 17). Se muestran además las dificultades de permanencia de los líderes pentecostales, tanto por las condiciones geográficas como por la circulación de la población, lo que induce a que la asistencia de los creyentes a los templos esté sujeta a condiciones estacionales: "siendo la segunda Iglesia en Bolivia, que está a 4.000 mts., sobre el nivel del mar y en la frontera con la República de Chile. Hemos tenido 4 Pastores, ahora es el $5^{\circ}$ Pastor que el Señor nos concede en esa amada Iglesia..." ("Primer grupo de ciclistas de la Iglesia en Villa Tunari-Bolivia”, 2003, p. 15).

De igual modo se realizan encuentros internacionales de mujeres en ciudades fronterizas del lado chileno, como Calama. "Dimos comienzo a la Primera Concentración Internacional de Dorcas ${ }^{7}$ realizada en Calama... contamos con la presencia del Pastor Juan Colque Ayma de la Iglesia en Villa Las Américas Bolivia... a esta Concentración se dieron cita delegaciones de 51 Iglesia, incluyendo hermanas de Perú, Bolivia y Argentina..." ("Avance de la obra en Calama”, 2000, p. 18). Estos encuentros fronterizos interiglesias (Argentina, Bolivia, Chile y Perú) de la IEP, que ellos llaman Concentración Internacional de Dorcas, estimularon nuevas formas específicas de vinculación entre indígenas fronterizos de los cuatro países. Lo interesante es que a un encuentro de mujeres sea invitado un pastor boliviano, lo que muestra la importancia que adquiere en la frontera chileno-boliviana la presencia de los creyentes de esta nacionalidad, que están dejando de ser solo colindantes al centro, sino que el centro es afectado ahora por lo fronterizo.

En la frontera se viven distintas experiencias religiosas "con gran manifestación del Espíritu Santo de Dios, el cual motivaba nuestros corazones, sin distinción de raza, color, ni fronteras, porque Jesús ha dado su vida por todos sin excepción" ("Misión de jóvenes de la iglesia de Sargento Aldea a la hermana República de Bolivia”, 1985, p. 7). Se resalta el carácter no-nacional de un encuentro evangélico al que asisten fieles de cuatro países, para quitarle la connotación nacionalista. También se resalta la identidad religiosa, subsumiendo a esta las identidades nacionales, étnicas y raciales. Este tipo de encuentros de manifestación de lo sagrado "permite que lo real se desvele, el mundo viene a la existencia" (Eliade, 1981, p. 18), en donde lo real no es plurinacional sino metanacional. Se resaltan nuevas

7 Nombre que llevan los grupos de mujeres en iglesias pentecostales. Se refiere al nombre de una mujer $\mathrm{He}-$ chos 9, 36-43, aludiendo a que es generosa y querida por la comunidad. 
fronteras simbólicas, ya no centradas en lo étnico y lo nacional, sino en lo fenomenológico de lo celeste y lo terrestre o lo de arriba y abajo, porque pese a estar en democracia, "lo blanco y lo indio continúan siendo fronteras simbólicas, que marcan distancias geográficas" (Del Cairo, 2003, p. 104) y por lo tanto una distancia cultural y una "configuración espacial que construye diferencia y reafirma el sentido del otro o de los otros en un contexto de subordinación o subalternidad" (Botero, 2008, p. 10).

Las fronteras se conciben históricamente, desde los centros, como espacios de enfrentamiento y en disputas permanentes, espacios amorfos y que tienen sentido solo en tanto son demarcatorios. Sin embargo, las fronteras se autoconciben como espacios de convivencia y cooperación, porque ellas develan proyectos sociales fundados en la heterogeneidad y liminalidad cuyos límites físicos son claros, pero no así los límites sociales y simbólicos. Por ello, ya sea en tiempos de crisis o de prosperidad, el desplazamiento de personas, en este caso de aymaras bolivianos a los valles del norte de Chile, continuó desplegándose (González, 1998a, 1998b), pero también de aymaras chilenos a Bolivia. Esto se puede apreciar en los relatos pentecostales: "en el año 1954 en Oyuni [Potosí], Bolivia, me encontraba trabajando en casa de un evangélico anciano. Allí el Señor me llamó y conocí el evangelio por primera vez...”. Esto sucedió en los primeros años de la Revolución de 1952 en Bolivia. Sin embargo, una década más tarde aparece en la zona de los valles de Chile: "en Pica, Chile, en 1964 enfermé gravemente siendo hospitalizada y perdí a mi hija... Clamé al Señor con mucho fervor, busqué el evangelio y me fui en busca de un Pastor hacia Iquique... regresé a mi hogar en Pica... El 19 de septiembre de 1965, me inscribí y recibí al Espíritu Santo junto a mis hijos, entré con mucha fuerza en el evangelio hasta el día de hoy". En estos testimonios se muestran los itinerarios de trabajo en los valles de Tarapacá en este caso, tal como lo afirma González (1998a, 1998b). Pero a la vez estos desplazamientos reflejan la búsqueda de sanidad en los templos pentecostales de Iquique, a través de la oración y la imposición de manos. Se puede apreciar que en estos procesos migratorios también se da una movilidad geográfica rural-urbana; urbana-urbana o rural-rural, más aún con el desarrollo de los polos urbanos costeros, lo que "dio un respiro económico al deprimido altiplano boliviano de Oruro. ${ }^{8}$ No sólo como puertas de entradas de productos, sino como nuevos mercados para exportar productos de altura como la quínoa y la carne de llama” (Albó, 2003, p. 112).

Como hemos señalado, el pentecostalismo de frontera se negó al anonimato. Creció notablemente, no construyó catedrales porque eran innecesarias en este contexto. No obstante, los pentecostales formaron un centenar de pequeñas comunidades, que más que templos eran hogares y familias, donde los feligreses se sentían a gusto porque les recordaba la realidad de la comunidad étnica o familia extendida. Esto pues el pentecostalismo de frontera se presentaba como una comunidad multiétnica y rescataba los capitales sociales, culturales y simbólicos del mundo altiplánico como la confianza, la cooperación, la convivencia y la resolución de conflictos centrada en la autoridad del Pastor, considerado y respetado como nueva autoridad étnica, y los aplicaba en la comunidad religiosa. Por tanto, en este contexto no importan los templos sino las casas-templos puestas a disposición por los indígenas conversos, que para los líderes indígenas eran suficientes ya que podían recurrir a la trashumancia, remembrando el pastoreo de la cultura altiplánica. Sin embargo, estas casastemplos para la ideología céntrica eran insuficientes, ya que no podían administrarlas ni traspasarlas al control del pentecostalismo del centro.

\section{Metaforización de las fronteras}

En su afán de constituirse en una religión legítima en la frontera chileno-boliviana, el pentecostalismo comienza a elaborar sus mitos fundacionales a partir de la simbolización del espacio social, concebido como territorios religiosos baldíos y representándolos con diferentes metáforas agrarias, marciales y metapolíticas. Además, como la frontera se

8 En los últimos años la movilidad fronteriza entre ChilePerú y entre Chile-Bolivia ha aumentado notablemente. Al respecto se puede consultar: Tapia, M., Liberona, N. y Contreras, Y. (2017); Tapia, M., (2015); Tapia, M. y González, A. (2014); Garcés, A., Moraga, J. y Maureira, M. (2016); Tapia (2013, 2015, 2017); Garcés (2016). Solo por nombrar algunos, ya que recientemente se han hecho trabajos de síntesis y análisis en materia de migración y movilidad. 
centrifica, las disputas por el control de la memoria aumentarán.

El primer misionero en llevar el pentecostalismo chileno a Bolivia fue el pastor Manuel González junto a su esposa e hijos, en el año 1939, a las ciudades de Cochabamba y Oruro. Dice el relato: “....[Dios] llama a su esposa, Zunilda Céspedes, como a Sara. Estaba dispuesta al llamado del Señor, pero no a dejar su Patria y cruzar la frontera. El Señor la enfermó gravemente... le mostró su tumba y/o Bolivia, a lo que ella contestó "Bolivia Señor"... para que Cambas, Vallunos y Collas, puedan llegar al conocimiento de esta riqueza insondable" ("Huellas de un misionero pentecostal en Bolivia”, 1985, pp. 5-8). En este relato se destacan tres elementos: en primer lugar, la ruptura de la representación de la mujer pentecostal como sumisa. El relato muestra a la mujer siendo parte en el viaje desde su hogar a la frontera, esto es, para "ir a otro mundo, un espacio extrańo, caótico, poblado de desconocidos y de extranjeros religiosos y transformar ese espacio en un lugar habitado y organizado, es decir: cosmizado" (Eliade, 1981, p. 8). En segundo lugar, vemos que aparece en el relato el dilema de la muerte o las misiones, o más bien la muerte física o la muerte simbólica, en tanto que al hogar de Zunilda se opone la irrelevancia de la frontera. En tercer lugar, se alude a una realidad cultural que presenta un importante componente de racismo, reduciéndosele a un conflicto regional. A la postre, tratándose de la realidad boliviana, la oposición no se limita solo a una distinción geográfica, sino que involucra clasificaciones culturales y sociales racistas que son ofensivas, humillantes y profundizan los resentimientos sociales. Solís y Martínez (2012, p. 27) afirman que "las zonas fronterizas se construyen a través de prácticas que, aunque descentradas, obedecen a lineamientos integrados a relaciones asimétricas de dominación". En ese sentido el pentecostalismo de centro al espiritualizar los problemas socioculturales de la frontera, los reduce a una lucha de divinidades. No obstante, en la medida que el pentecostalismo de centro se fronteriza, lo sociocultural afecta lo espiritual y logra constituirse en un nuevo tipo de pentecostalismo. Pero desde la construcción de la memoria, el centro concibe esta coexistencia entre cultura local y pentecostalismo de frontera como un producto del centro.
Como destaca Rivera, "la dinámica religiosa es recreada por los actores que habitan una frontera heterogénea en desigualdad y asimetría estructural, en medio de la cual la religión proyecta unos preceptos que han servido para construir territorios devocionales que configuran una geografía religiosa” (Rivera, 2014, p. 98). De ahí que los pentecostales proyecten su optimismo, aunque ilusorio, para superar el racismo, a partir de conversiones individuales y familiares, utilizando varias metáforas:

a) Metáforas agrarias. "Para el hombre religioso, la Naturaleza nunca es exclusivamente 'natural': está siempre cargada de un valor religioso" (Eliade, 1981, p. 31). Por ello se dice: “...llegó desde Chile... Manuel González, para sembrar la simiente divina en estas regiones de Cochabamba y Oruro que ya estaban blancas para la siega..." ("Reseña de estudio bíblico internacional de pastores realizado en Oruro-Bolivia”, 1994, pp. 6-7). Las metáforas usadas como "sembrar la simiente divina"; "blancas para la siega" y "fruto autóctono" dan cuenta de la importancia del imaginario rural y campesino que resulta significativo en un contexto indígena, quienes siempre transitan entre lo urbano y lo rural, sobre todo, la primera generación de indígenas migrantes pentecostales. Constantemente hay un doble debate sobre las fronteras: "por un lado, el debate es dónde colocar fronteras, y por otro, cuándo pretender cruzarlas, debilitarlas, asumirlas reflexivamente o reforzarlas" (Grimson, 2003, p. 22). Se resaltan las metáforas agrarias evidenciando el origen rural del pentecostalismo chileno ${ }^{9}$ importante para la década del treinta cuando se iniciaron las misiones pentecostales chilenas en Bolivia, pero no para la década del ochenta cuando en Chile el proceso migratorio rural-urbano ya se había consolidado, pero seguía y sigue siendo un proceso importante para Bolivia. En este tránsito rural-urbano el indígena es concebido como un rival, aquel que viene con costumbres extrañas de la otra rivera. Entonces el pentecostalismo se presenta simbólicamente como puente, entre campo y ciudad, entre lo indígena y lo mestizo.

b) Metáforas marciales y fanales. Así como existe una permanente guerra y lucha en el mundo visible,

9 Este origen del pentecostalismo ha sido bien desarrollado por D’Epinay (1968) y Mansilla (2016). 
también la hay en el mundo invisible, "es una eterna lucha entre el cosmos y el caos" (Eliade, 1981, p. 21). Por ello los pentecostales utilizan estas metáforas marciales, al representar a los predicadores como militares que luchan contra el caos. El "Pastor Manuel Fco. González y su esposa e hijos llegaron a Oruro en 1939 [...] Predicando como un valiente soldado, que en esos tiempos era difícil la predicación del evangelio por las calles, pero gracias a esa antorcha, encendida, la voz del evangelio penetró a los sitios más difíciles" ("Consagración de tres locales de predicación de la iglesia de Oruro, Bolivia. Locales: Vinto-Toledo-y Ankola”, 1985, pp. 10-11). El soldado, al igual que el agricultor, son metáforas que se vinculan al obrero, y por lo tanto a la pobreza. Pero también al ser leído desde un contexto de dictadura militar, al pastor-misionero se le representa como un militar que pelea y conquista fronteras y que "sólo mediante las prácticas sustentadas por los individuos concretos son posibles los cruces de límites, es decir, la construcción simbólica de fronteras" (Solís y Martínez, 2012, p. 13). Desde el centro se conciben estas luchas como propias del espacio fronterizo, en donde las fuerzas caóticas quieren mantener y extender sus fuerzas grisáceas, para impedir la extensión de la luz del centro.

c) Metáforas supranacionales. Dado que el centro siempre quiere extender sus límites, entonces considera que las fronteras son conflictos, pero las fronteras se resisten al imaginario concéntrico y por lo tanto el centro considera necesaria la lucha abanderizada entre la luz y las tinieblas, es decir, el centro y la frontera. Se resalta la "abnegada labor de Daniel Salguero, primer fruto autóctono del esforzado pionero chileno, quien por espacio de más de veinte ańos mantuvo en alto la bandera del evangelio entre Oruro y La Paz" (Fuego de Pentecostés, núm. 779, pp. $6-7,1994)$. La "bandera del evangelio" se presenta como emblema que permite superar los conflictos internacionales desdibujando la distinción nacional y esbozando una nueva comunidad supranacional. La estrategia más efectiva del pentecostalismo chileno en la frontera chileno-boliviana fue reconocer el liderazgo local a lo que ellos llaman "frutos autóctonos". De este modo el pentecostalismo se descentra para resaltar la frontera. El centro se diluye; sin embargo, más adelante este vuelve a condensarse como centro. d) Metáforas metanacionales. Lo nacional es considerado como tinieblas que opacan la luz, por ello necesitan disolver lo nacional en metanacional, para decir que: "cumplida la misión en Bolivia, con la bandera del Evangelio de Paz izada al tope en las importantes ciudades de Oruro (Vinto, Toledo, Ancokal) y Cochabamba, regresaron los valientes y abnegados misioneros González-Céspedes, a su país en el año $1947 \ldots$ otros valientes soldados... sembrando la preciosa semilla en pueblos como Vinto, Toledo, Ancokal (Oruro)... damos infinitas gracias a Dios por las oraciones de las amadas iglesias de Chile, que se sienten en Bolivia” "“Consagración de tres locales de predicación de la iglesia de Oruro, Bolivia. Locales: Vinto-Toledo-y Ankola”, 1985, pp. 10-11). La bandera (nacional) es reemplazada por la bandera del evangelio, aludiendo así a la idea de un solo pueblo. Con este imaginario se intenta romper el imaginario nacionalista para configurar un metanacionalismo espiritual. Se intenta superar la chilenidad y la bolivianidad en las prédicas. También se procura superar las solidaridades militaristas nacionalistas, por consiguiente, un predicador viene a ser un militar agricultor. Como destaca Rivera, "desde la perspectiva sociocultural se observa el espacio en el marco de una geografía de espacio-tiempo, como actos repetitivos, cotidianos de los lugares, en vez de un territorio fragmentado por una línea de dos estados nacionales" (Rivera, 2014, p. 98).

Los cambios religiosos van acompañados por la negación, pero a la vez la legitimación de nuevas fronteras culturales, y en este sentido se autoconciben como minorías perseguidas: "En esta ciudad altiplánica (Chapallata), ${ }^{10}$ se ha establecido una Iglesia Evangélica Pentecostal... se trabajó esforzadamente y con oposición de las autoridades civiles, pero logra construir una casa de oración, su casa pastoral y muchos circuitos en las poblaciones aledañas..." ("Reseña de la Conferencia Internacional de Pastores en Challapata, República de Bolivia”, 1997, p. 7). Se destaca, una vez más, la oposición política, pero también el crecimiento que el pentecostalismo chileno tuvo en algunas ciudades bolivianas. La "construcción de fronteras no solo se realiza en los

10 Challapata es capital de la provincia Aravoa del Departamento de Oruro, situada a $120 \mathrm{~km}$ de Oruro y paso obligado hacia Potosí. 
límites de la comunidad, sino también al interior de la misma” (Solís y Martínez, 2012, p. 16); por tanto, el "nosotros" es percibido desde el interior como víctimas perseguidas: ahora ese "nosotros" se refiere a indígenas pentecostales. En consecuencia, la noción de frontera tiene un sentido espacial pluridimensional, relacional y poroso.

Desde el centro el crecimiento pentecostal es atribuido al tesón de los misioneros chilenos: "en Oruro nuevamente había que empezar a trabajar con fe... cuando él dirigía la obra de construcciones (contratista), una hora antes de la señalada, tocaba la campana y reunía a la gente que trabajaba con él y los evangelizaba. ...La hermana Zunilda se hizo una cholita (mujer típica de la región) más entre ellos y se ganó el cariño y confianza de un pueblo difícil de conquistar" ("Huellas de un misionero pentecostal en Bolivia", 1985, p. 6). Uno de los aspectos significativos es cómo el pentecostalismo excluye a las mujeres de los mitos fundacionales. Pero aquí aparece como atisbo, porque Bolivia aún es espacio fronterizo simbólico; no obstante, después las referentes femeninas son nombradas, pero no destacadas, y arrojadas al silencio, lo invisible y lo grisáceo. Zunilda, la esposa del pastor misionero Manuel González, es resaltada por su supuesta adaptación cultural del "ser mujer": se hizo una "cholita más". Así la mujer es imaginada en su rol tradicional, mujer-cultura, consiguientemente adaptable a la frontera.

El siguiente relato se refiere a la muerte de Zunilda, en que las iglesias bolivianas no fueron invitadas: "Por eso ahora nosotros, 'tus hijos, tus bolivianitos', como nos llamabas, no pudimos estar en tus funerales por no estar avisados, pero hoy, a un año de partida, depositamos este pequeño y humilde ramo de ' 27 flores', tomados de tu jardín que un día plantaste, blancas azucenas matizados y Kantutas tricolor, flores de tu segunda patria" ("Huellas de un misionero pentecostal en Bolivia", 1985, p. 8). La expresión "bolivianitos" es ofensiva para los bolivianos porque los infantiliza, sin embargo, aquí la asumen pues se refieren a la forma cariñosa en que Zunilda los llamaba. Las 27 flores representan a las 27 mujeres que eran parte de la congregación fundada por Zunilda y su esposo, el pastor Manuel González. La comunidad supranacional, que se intenta construir desde el centro, está siempre proyec- tando el imaginario superior e inferior, porque en "las zonas fronterizas están convocados los procesos de dominación, subordinación y también los de resistencia y contra-hegemonía” (Solís y Martínez, 2012, p. 16). Según eso, el pentecostalismo fronterizo reclama integración en los hitos históricos de la institución.

El pentecostalismo de centro, por una parte reduce la frontera al conflicto y por otra interpreta el conflicto desde una dimensión puramente espiritual, pretendiendo resolver esos conflictos desde la conversión de los individuos, obviando los problemas históricos, culturales y sociales del territorio. No obstante, la frontera se enfrenta con estos conflictos e intenta superarlos presentando la comunidad religiosa como una nueva forma de enfrentar el futuro. Lo más significativo en este espacio es la incorporación de la mujer al liderazgo, a espaldas del centro. En la medida que el liderazgo crece y se expande se van produciendo nuevos espacios céntricos y de fronterización. Lo interesante de este proceso es que centro y frontera no son espacios extremos sino coexistentes.

\section{La indeterminación entre las fronteras nacionales y las culturales: la altiplanización del pentecostalismo}

La frontera "es una zona de encuentro entre dos o más culturas, es una interacción entre culturas diferentes. La naturaleza de estas culturas interactivas se combina en el entorno físico para producir una dinámica que es única en el tiempo y en el espacio" (Londońo, 2003, p. 80). Reconociendo la cultura y la religión en las fronteras como procesos dinámicos, complejos y relacionales, el pentecostalismo del centro en Bolivia intenta chilenizar, pero a la vez también se indigeniza, ${ }^{11}$ específicamente se "altiplaniza". ${ }^{12}$ Las comunidades aymaras y quechuas viviendo en el norte de Chile y en Bolivia

11 La indigenización del pentecostalismo es un proceso que se ha observado en otros contextos indígenas. $\mathrm{Al}$ respecto ver Miller, E., 1979; Muratorio, B., 1982; Garma, C., 1985, 1987.

12 Cuando decimos que se altiplaniza, decimos que se aymariza y quechuariza. 
representan una unidad cultural, por lo tanto, el hecho de que estén separadas por una la frontera física chileno-boliviana no incide en este sentido unitario. Por eso afirmamos que, al insertar el pentecostalismo de centro en los territorios fronterizos entre Chile y Bolivia, este experimenta una "altiplanización".

Uno de los grandes problemas de la IEP en Bolivia fue su énfasis chilecentrista, algo que también incorporan los líderes bolivianos, pero que en la medida que aparecen nuevos liderazgos, más influenciados por los líderes locales, serán críticos de esa postura, desembocando en el gran cisma de la IEP en Bolivia en el año 2007. "Por motivos muy poderosos no pudimos visitar todas nuestras iglesias en la hermana República de Bolivia, pero tenemos conciencia de que en todas ellas esperan misioneros chilenos. Estos campos son aptos para la juventud para ir y llevar el mensaje de salvación" ("Misión de jóvenes de la iglesia de Sargento Aldea a la hermana República de Bolivia”, 1985, pp. 6-7). La IEP, como toda religión misionera, manifiesta la ideología colonizadora: el sentido de superioridad sobre los misionados, como la gran frontera simbólica, expresión de "relaciones interculturales asimétricas que expresan la vigencia de las fronteras étnicas" (Bartolomé, 2008, p. 39). Además, intenta "roturar una tierra inculta, de conquistar y de ocupar un territorio ya habitado por 'otros seres' humanos: la toma de posesión ritual debe en uno u otro caso repetir la cosmogonía" (Eliade, 1981, p. 9): antes el caos y ahora el cosmos, antes el paganismo y ahora el pentecostalismo.

Se manifiesta una maternalización de lo religioso, como sombra imaginaria de la Pachamama "...en Alto Beni (Nor Yungas), una región muy lejos de Caranavi... el templo está construido faltan algunos detalles para su consagración. Aquí en este edén terrenal se derramó el poder pentecostal con un gran avivamiento...nuevas almas se están convirtiendo... son fruto de la madre Iglesia" ("Inauguración de un nuevo templo de la Iglesia en Caranavi La Paz- Bolivia”, 1997, p. 10). Se describe una belleza edénica, porque se trata de una región con una importante diversidad ecosistémica de animales, vegetales y muy rica en diversidad de frutas. Se resalta además el carácter femenino de la Tierra y la frontera, porque "la mujer está, pues, solidarizada místicamente con la Tierra”. (Eliade, 1981, p. 39). En este escenario es donde se realza el éxito misionero y se hace una relectura desde el Antiguo Testamento. Así, "el territorio demarca la instauración de las fronteras como aquellos intersticios donde ocurre la influencia de un poder específico y se dimensionan horizontes sujetos a nuevos poderes" (Del Cairo, 2003, p. 104). De esta manera la rivalidad entre el centro y la frontera se simboliza en el plano arquetípico con la disputa entre lo femenino (frontera) y lo masculino (centro).

En la ciudad de El Alto en La Paz, "se levanta radiante la voz de la Iglesia Evangélica Pentecostal. En 1978 fue trasladado el Pastor Nolberto Villca Villca de la Iglesia de Sabaya a la ciudad de el Alto La Paz... no habiendo propiedad ni hermanos, pero, alquiló una casa de oración ubicada en barrio minero Villa Tejada... haciendo reuniones de culto, además sirvió de dormitorio y comedor para el Pastor" ("Huellas de un misionero pentecostal en Bolivia", 1985, pp. 5-8). Se destaca la participación del pastor Norberto Vilca Vilca, uno de los grandes gestores del pentecostalismo chileno en el mundo aymara, del lado de Bolivia, quien de Sabaya es trasladado a La Paz en el ańo 1978. Debido a su capacidad de liderazgo y su dominio de la lengua aymara tiene éxito en la predicación, sea cual sea el templo que él dirija. "Pasó un año y el Señor Jesús le honró como primer Presbítero en Bolivia. Después Él le concedió una propiedad donada por el hermano Severo Juaquira, también fue donada por la madre Iglesia en Chile, una ofrenda para la construcción de la casa pastoral" ("Huellas de un misionero pentecostal en Bolivia”, 1985, pp. 5-8). En este relato se manifies$\tan$ dos aspectos. Uno tiene que ver con la maternalización de la Iglesia emulando la Pachamama de los aymaras. Así la mujer es "solidarizada místicamente con la Tierra. La sacralidad de la mujer depende de la santidad de la tierra. La fecundidad femenina tiene un modelo cósmico: el de la Terra Mater, la Genetrix universal' (Eliade, 1981, p. 39).

En segundo lugar, se hace referencia al imaginario colonialista de la IEP, algo contra lo cual el pentecostalismo tanto luchó, oponiéndose a un protestantismo misionero. "El Pastor fue trasladado a Cochabamba, donde la dicha Iglesia era pastoreada por Mateo Colque y Alfonso Colque, nuevamente 
le concede por segunda vez al Pastor Nolberto Villca para pastorear, trabajar, con más ahínco con la construcción y por las almas" ("Huellas de un misionero pentecostal en Bolivia”, 1985, pp. 5-8) . El permanente traslado de los líderes es una estrategia que utiliza la IEP para evitar que el pastor genere arraigo y apego con la congregación y después un posterior cisma. Es la desconfianza del centro hacia la frontera, es "el lugar de transición, tensión, negociación y convergencia de dos o más formas de territorialización" (Del Cairo, 2003, p. 104).

El pentecostalismo de centro acopla diferentes mitos para pretextar la chilenización del pentecostalismo indígena altiplánico: ${ }^{13}$ "Caranavi, corazón de los Yungas paseños... delicia de los hijos del Choqueyapu... montañas llenas de grandes bosques: el eco pentecostal repercute. Por ende debemos recordar a los esforzados misioneros que han extendido la promesa de Dios hecha a su pueblo en gran avivamiento de 1909 en Valparaíso..." ("Noticias de la obra del Señor en la Región Yungueñas", 1996, p. 12). ${ }^{14} \mathrm{Se}$ vinculan relatos bíblicos, mito fundacional pentecostal y concepción paradisíaca del espacio. Los mitos se unen a través de un árbol de frutos, en donde "el árbol ha llegado a expresar todo lo que el hombre religioso considera real y sagrado por excelencia, para coger los frutos hay que enfrentarse con el monstruo guardián y matarlo; hay que soportar, por tanto, una prueba iniciática de tipo heroico: el vencedor adquiere por la 'violencia' la condición sobrehumana, casi divina, de la eterna juventud, de la invencibilidad y la omnipotencia" (Eliade, 1981, p. 41). En consecuencia, el pentecostalismo de centro se autoconcibe como forestador y concibe al pentecostalismo de frontera como tierra de forestación. Por consiguiente, la frontera es un espacio paradisíaco que necesita ser transformado en un paraíso de almas, y para fundamentar esta forestación simbólica recurren a su mito fundacional. "El 6 de enero de 1981, por pri-

13 Por ello se recurre al avivamiento fundacional del pentecostalismo chileno en Valparaíso liderado por Hoover. Valparaíso es la cuna del protestantismo misionero liderado por David Trumbull, y además es la cuna del pentecostalismo chileno.

14 Aquí se hace referencia a una pequeña ciudad distante a 150 km de la ciudad de la Paz; es una ciudad que confluye camino a la Amazonía, por ello el relato destaca su belleza y recurre al historial de los distintos mitos. mera vez el Señor envió misioneros voluntarios de la Iglesia Evangélica Pentecostal de Huachacalla... para sembrar la semilla en esas tierras áridas, donde brotó una planta para el Seńor; y fue regada constantemente enviando mensajeros de Dios" "“Consagración del Templo en San José de Kala. Iglesia en Huachacalla, República de Bolivia”, 1989, p. 8). Huachacalla es un municipio perteneciente a la ciudad de Oruro. $\mathrm{El}$ "territorio demarca la instauración de las fronteras como aquellos intersticios donde cesa la implementación de un poder específico y se dimensionan horizontes sujetos a nuevos poderes" (Del Cairo, 2003, p. 104); en el que se emplean metáforas seminales para concebir las fronteras como tierras áridas donde el centro siembra semillas arbóreas que revitalizan la tierra y pasan del invierno a la primavera.

Cuando el pentecostalismo de frontera comienza a crecer y extenderse, es incluido por el centro en el mito fundacional institucional, pero interpretado, elaborado y seleccionado por líderes céntricos, olvidando la autonomía fronteriza, no reconociendo a los líderes locales, especialmente el rol de las mujeres. No obstante, las mismas descripciones que rememoran en estas memorias muestran la autonomía y la suficiencia de la frontera, dando cuenta de que su crecimiento no se debe a la acción foránea sino a la autonomía relativa de los líderes locales, la riqueza de sus medios y la acción concertada, reflexiva y transformadora del sujeto local.

\section{El uso de las lenguas indígenas como fronterización simbólica}

Xavier Albó hace referencia a las tensiones que vivían los aymaras chilenos a fines de la década del ochenta (1988), afirmando que aquellas tensiones repercutían hasta las fronteras bolivianas. En efecto, el autor destaca que "el CENSO de Bolivia 1992 demuestra que los grupos rurales aymaras que más avergonzados eran de su origen, o al menos de su lengua materna, son los que viven en la frontera chilena. En parte por la dura experiencia que sufren cuando acuden a Chile a trabajar como trabajadores temporales" (Albó, 2003 , p. 115). En cambio en lugares más alejados de las fronteras chilenas, los relatos pentecostales muestran que los cultos eran espacios donde la lengua aymara se desarrollaba muy bien: 
[...] emprendimos nuestra anhelada misión con un grupo de 13 jóvenes... llegamos a la iglesia de Arica... recibimos fuerzas del Señor para remontar el Altiplano Boliviano... nos trasladamos a la iglesia de Sacaba... La mayoría de esos hermanos no hablan castellano, pero nos gozábamos de alabar al mismo Dios... Después a Canteras, donde nuevamente pudimos apreciar el gran cariño que sienten los amados hermanos bolivianos por sus hermanos chilenos ("Consagración de tres locales de predicación de la iglesia de Oruro, Bolivia. Locales: Vinto-Toledo-y Ankola”, 1985, p. 6).

Aquí se habla de una ciudad perteneciente al Departamento de Cochabamba, con alta población aymaraparlante, porque para "el hombre religioso, el Cosmos vive y habla” (Eliade, 1981, p. 45), y por lo tanto, la prédica y la práctica religiosa deben ser en el idioma vernáculo.

En esta recreación seminal entre el centro y la frontera, el desierto y el vergel, el invierno y la primavera, la semilla germina y nacen nuevos árboles, representando "almas salvadas". Entonces, "el mundo entero, simbólicamente, regresa, con el neófito, a la Noche cósmica, para poder ser creado de nuevo, es decir, para poder ser regenerado" (Eliade, 1981, p. 53). En otro relato se destaca: "Dios ha bendecido esa Iglesia con muchas almas salvadas, la asistencia fue de 216. El Pastor Abelino Aguilar los hacía cantar alabanzas al Señor en Quechua, Aymara y Castellano; el culto fue muy maravilloso" ("Viaje Misionero al sur de Bolivia”, 1988, p. 10). En la germinación de "almas salvadas", hay que "abolir la obra del Tiempo, reintegrar el instante auroral anterior a la Creación: en el plano humano esto equivale a decir que es preciso volver a la 'página en blanco' de la existencia, al comienzo absoluto, cuando todavía nada estaba mancillado, estropeado" (Eliade, 1981, p. 53). En este caso se habla del pastor Abelino Aguilar, quien comprendió que una de las razones por las que el pentecostalismo chileno logró asentarse en la zona indígena aymara y quechua fue que las reuniones y cultos eran llevados a cabo en los idiomas vernáculos. "La imagen del árbol no se ha escogido únicamente para simbolizar el Cosmos, sino también para expresar la vida, la juventud, la inmortalidad, la sabiduría" (Eliade, 1981, p. 41). Es una manifestación de que "la demarcación fronteriza no separa lenguas, culturas y grupos humanos sino estados nacionales" (Nolasco, 1992, p. 10). En este contexto la religión hace uso del idioma como un proceso de desfronterización y refronterización a la vez. Lo primero sucede porque usa la lengua como recurso de evangelización y lo acerca a la cultura; y lo segundo, porque se produce un proceso de diferenciación entre los indígenas, pero también del pentecostalismo del centro.

Otro relato destaca: "el año 1967, llegó mi pastor Eustaquio Ayaviri... me instó a buscar más de cerca a Dios... y mi buen Dios me honró como profesora de la Clase [bíblica] en Quechua" ("Jehová guarda”, 1985, p. 12). Se destaca la valentía del pastor Eustaquio Ayaviri por valorar el idioma quechua para enseñar la Biblia. Pero no solo la Biblia cumplía esta función transmisora del idioma, también los himnarios. Es interesante ver cómo los indígenas logran ser parte de cultos evangélicos ofrecidos en tres idiomas: quechua, aymara y español. "Se habla de fronteras simbólicas porque son límites invisibles; paradójicamente unen, dividen, acercan a 'otro' y separan de la 'otredad'” (Paniagua, 2002, p. 144). En este caso la fronterización simbólica del pentecostalismo une a través del uso de la lengua.

...salimos a misión desde nuestra Iglesia en Cerro Verde-Cochabamba. Viajamos a la ciudad de La Paz-Bolivia y nos fuimos a Puno y desde allí a Arequipa-Perú... Después a Tacna... llegamos a Arica. Desde Arica viajamos a Santiago. Primero a Puente Alto... estuvimos en la amada Iglesia en Sargento Aldea, qué gozo más grande juntarnos en comunión con tantos jóvenes y aprender de ellos en silencio lo que nos hace falta en Bolivia... 8 de octubre, estuvimos en la Iglesia de Maipú... 9 de octubre, en la Iglesia en La Cisterna... 10 en la Iglesia en Renca... 11 en Iglesia en Núñoa... Desde Nunnoa nos fuimos a Antofagasta y de ahí a Calama... Viajamos a Oruro-Bolivia... y el 17 de octubre, llegamos a Cerro Verde-Cochabamba ("Misión de jóvenes Bolivianos al Perú y Chile", 1990, p. 15). 
En el relato aparece otro aspecto significativo de la cultura organizacional pentecostal, que tiene que ver con las llamadas Juntas Misioneras. Su relevancia está en la oportunidad que brinda a los jóvenes pobres durante la década del ochenta de transitar por las redes de templos entre Bolivia, Perú y Chile. Como destaca Rivera, "la religiosidad se posiciona, a través de la creencia y la práctica, frente a una cultura territorial construida históricamente, pero moldeada recurrentemente según los intereses, necesidades, planes y coyunturas" (Rivera, 2014, p. 106). Al respecto señala que

[en] Aramasi ${ }^{15} \ldots$...conocida como el granero de Bolivia, el quechua predomina en un $100 \%$. Ha sido un lugar donde... el Pastor Eustaquio Ayaviri por el año 1973, luego el Pastor Ricardo Saca Cota el año 1986, juntamente con los hermanos, quienes como lugareños sufrieron una paliza de muerte, pues, utilizaron para atacarlos aún armas de fuego...han predicado el evangelio" ("Consagración de dos nuevos templos de la Iglesia en Villa Pagador, Bolivia”, 1994, p. 13).

El relato describe la localidad quechua como "el granero de Bolivia”, resaltando el valor que tiene el liderazgo del pastor quechua Eustaquio Ayaviri, pero además se destacan los conflictos que tuvieron en el lugar, problemas que los pentecostales han experimentado en las distintas comunidades indígenas. Es una manifestación de que "el paisaje humano, móvil y en expansión demarca el territorio apropiado por los sujetos religiosos" (Rivera, 2014, p. 106), pero dicha apropiación está siempre acompañada de resistencia y conflicto. Los pentecostales presentan esta reacción de la comunidad como recurso simbólico para legitimarse como religión ante ella. El creyente indígena nunca ha sido un ser pasivo frente a los mensajes religiosos (Garma y Embriz, 1994, p. 39), más bien los indígenas conversos son sujetos sociales que seleccionan creencias, prácticas y ofertas religiosas en función de sus estrategias y recursos en concordancia con su espacio social y cultural preexistente.

15 Estancia Aramasi es un lugar que está ubicado a $60 \mathrm{~km}$ del Departamento de Cochabamba, que se encuentra a una altitud de $3046 \mathrm{msnm}$.
En la medida que el pentecostalismo chileno en Bolivia quedaba en manos de los líderes bolivianos, de origen aymara o quechua, los cultos tendían a ser más indigenizados. No obstante, el pentecostalismo se ha valido de la tradición católica y protestante en el uso de los libros sagrados traducidos al aymara ${ }^{16}$ y quechua ${ }^{17}$ (la Biblia, el Nuevo Testamento, himnarios). Con el liderazgo indígena pentecostal comienzan a insertarse ritualidades y cosmovisiones indígenas. Dado que la conversión no significa la desaparición de la identidad anterior, aunque el converso lo niegue, ella sigue presente. Esto es lo que podemos observar en el contexto aymara:

[...] salimos al desierto en ayuno; hasta las faldas de esos cerros blancos de nieve del Huayna Potosí... Escalamos adultos, jóvenes y niños, un número de 27 con el Señor, oramos tres veces al día, con nuestras rodillas sobre las pequeñas pajas bravas (piedras) húmedas de blanca nieve, en un ambiente de fuertes ráfagas de viento frioso ("Mis agradecimientos al Dios Todopoderoso", 1989, p. 12).

16 La primera traducción bíblica hecha en América "corresponde a Vicente Pazos Kanki, nacido en 1779 en el Alto Perú, lo que es ahora Bolivia, y fallecido en Buenos Aires en 1853. Pazos Kanki, además de ser escritor y político, fue también sacerdote católico. En 1817 partió exiliado a Londres. En 1825 aceptó la propuesta de Diego Thomson de traducir el Nuevo Testamento al aymara. La traducción concluyó a fines de 1826. El Evangelio de Lucas fue publicado en 1828, y fue el primer evangelio traducido a un idioma autóctono de América del Sur. Luego se traduce El NT en 1954 y la Biblia fue publicada por primera vez en 1986". Tomado de: http:// www.traducciondelabiblia.org/noticias/aymara/

17 En 1880 Evangelio de Juan, por Jorge Alán; en 1923 Nuevo Testamento, traducido por Jorge Alán y Crisólogo Barron; en 1944 Nuevo Testamento revisado por un equipo de nativohablantes; en 1978 Nuevo Testamento edición bilingüe castellano/quechua: "Diosmanta K'alapurka J'akalawa Uchuku Sumaj Willaycuna Runapaj”, revisado por nativohablantes; en 1986 la Biblia "Qhweshwa Biblia" con CD, trabajo realizado en conjunto con traductores católicos; y en 1996 la Biblia "Diosmanta Qhelqasqa", revisión realizado por un equipo interconfesional. Tomado de: http://www. traducciondelabiblia.org/noticias/revision_de_la_biblia_quechua_central_de_bolivia/ 
De esto era que nos habló Rivière cuando nos decía sobre la resignificación de los espacios, mitos y ritos aymaras que estaba realizando el pentecostalismo en el altiplano boliviano (Rivière, 1998, 2004), en este caso la resignificación del desierto y los cerros para ayunar y orar como comunidad étnico-religiosa.

Sin embargo, también encontramos los conflictos que el pentecostalismo ha tenido con la incomprensión y la intolerancia de las festividades indígenas, destacados por investigadores en ciertos contextos culturales.

\section{La Fiesta de la Ch'alla}

¿Tras la prosperidad y el bienestar?

¿Qué quiere decir carnaval? Quiere decir ¡es carne a Baal! ¿Sabe cuál es el otro nombre de Satanás? La Biblia también lo llama Baal- Zebub (Hebreo: Señor de las Moscas) como una alteración de Baal- Zebul (Hebreo: Príncipe Baal). En San Mateo 12:24, se le llama Beelzebú (Griego: Príncipe de los demonios). "Llegó el carnaval, y toda la gente se prepara para hacer "la ch'alla". Las empresas públicas, como privadas "ch’allan" sus edificios, máquinas y todas sus cosas. Las casas se adornan con serpentinas y mixturas. Todo esto lo hace la gente para que le vaya bien y tenga prosperidad. Si no lo hace, las cosas irán mal, los poderes de los espíritus le castigarán con desgracias y fracaso. Pero, ¿es correcto hacer ch'alla en carnavales o en otras ocasiones importantes como: El techado en casa, la inauguración de obras, nuevas movilidades, comienzo de negocios, comienzo de actividades, ¿y muchas otras cosas? Hacer ch'alla es el acto de hacer beber y comer a la Pachamama, la diosa tierra; la casa o "condor, sapo, culebra"; y otras cosas más, en las que se cree que se encuentran los espíritus sustentadores, con el objeto de conseguir la prosperidad y el bienestar en sus actividades económicas. La gente está convencida y acostumbrada de que si no lo hace le pasará cualquier desgracia como venganza de los poderes espirituales a quienes no han "challado". Esta costumbre, no solamente la practican los aymaras o quechuas, sino que lo hacen, incluso, en las zonas llamadas residenciales. ("La fiesta de la Ch'Alla. ¿Tras la prosperidad y el bienestar?”, 2005, p. 9)

En este relato se presenta uno de los dilemas que más conflictos ha provocado en el pentecostalismo entre las comunidades indígenas: la demonización de las tradiciones étnicas más importantes, como la Challa. Una de las festividades que más competencia y resistencia presenta al pentecostalismo es el Carnaval de Oruro, que tanta influencia ha tenido en Bolivia, en el Norte Grande de Chile y en otros países donde han migrado los bolivianos. Pero lo más llamativo es la interpretación errónea frente al origen de la palabra 'carnaval', para conducirla a la demonización, con el fin de considerar a las otras divinidades como parte del Caos, y la divinidad propia como el Cosmos. "La instalación en un territorio reitera la cosmogonía" (Eliade, 1981, p. 13), porque el pentecostalismo, como toda religión, crea y recrea fronteras simbólicas para diferenciarse y distinguirse de los universos simbólicos preexistentes. Debido a que "las fronteras son contingente, se recrean a partir de las prácticas dadas en un contexto social" (Solís y Martínez, 2012, p. 12). Establecer fronteras es por tanto apropiarse de un espacio objetiva y subjetivamente; en ese sentido "lo simbólico es el espacio subjetivado" (Ibíd.).

En consecuencia, uno de los elementos centrales del pentecostalismo de frontera ha sido considerar la cultura local como medio y recurso para la predicación y conversión. Así, los ritos, mitos, creencias y capitales lingüísticos fueron canalizados, tomados de, y por, la cultura, en permanente tensión entre las "viejas creencias" y las "nuevas creencias". La eficacia simbólica de la frontera pudo concretarse en razón del dinamismo entre cultura y religión.

\section{Conclusiones}

En el presente texto mostramos la diversidad de procesos de fronterización simbólica según se pueden colegir en el material bibliográfico de la revista Fuego de Pentecostés. Expusimos cómo dichos procesos se 
despliegan en distintos ámbitos y niveles: la metaforización de la figura de los pastores en la frontera permitió al pentecostalismo central apropiarse de los procesos de conversión y presentar la expansión en el norte como parte de la misión institucional centralizada. El establecimiento de templos por parte del pentecostalismo de frontera permitió producir espacios sagrados e identidades supranacionales allí donde regularmente se enfatiza el carácter profano y se nos recuerda la pertenencia y subordinación a un Estado-nación. Las metáforas agrarias, marciales y fanales, con su carácter supranacional y metanacional, producen imaginarios que autorizan una permeabilidad de las fronteras. El carácter supranacional del ser andino está en la base de dinámicas propias, como la maternalización del imaginario o las metáforas de forestación que el centro impone hacia este territorio adusto.

La especificidad de estos procesos nos ha llevado a caracterizar un pentecostalismo fronterizo, en oposición a un pentecostalismo de centro, y además, a sostener la tesis de una altiplanización del pentecostalismo, subrayando los elementos culturales propios aymaras y quechuas presentes en ellos. Como observamos, en las relaciones entre el centro y la periferia se despliegan procesos dinámicos, en los cuales la función simbólica tanto de los pastores, de los templos, del imaginario y de la lengua, adquiere una función de metaforización de las dinámicas sociales más amplias, actualizando en lo simbólico las relaciones entre el centro y la periferia, y produciendo la frontera como espacio de disputa simbólica y de reformulación de sentidos y prácticas a través de las cuales los grupos configuran y reconfiguran sus identidades según lógicas específicas de altiplanización del pentecostalismo.

Un ejemplo muy significativo ha sido el proceso de constitución del pentecostalismo como espacio para el desarrollo de la lengua aymara. Este ejemplo presenta una paradoja para una postura teórica esencialista: la aparente contradicción de que unas prácticas que han contribuido tanto a la desarticulación y desintegración de ciertos elementos culturales del mundo andino terminen fortaleciendo un aspecto central de la cosmovisión como son las lenguas originarias. Estos procesos cuestionan la identificación entre lengua y cosmovisión indígena e invitan a pensar nuevas formas de conceptualizar el potencial heurístico que tiene el estudio de los procesos de fronterización simbólica para cuestionar los fundamentos más básicos de las aproximaciones tradicionales.

En síntesis, la ideología céntrica se negó a disminuir su relevancia en la frontera. La frontera, a su vez, buscó diferenciarse del centro, a lo que contribuyó tanto la elaboración de refundaciones simbólicas desde el centro como desde las fronteras. Así, las fronteras se vuelven centros y los centros, fronteras. Adicionalmente, también los centros tienen sus fronteras, así como las fronteras tienen sus centros, demostrando estos procesos el dinamismo de los espacios sociales y culturales, generándose de este modo una mutua apropiación simbólica del espacio.

\section{Agradecimientos}

El presente artículo es parte de los resultados del proyecto FONDECYT de Iniciación 11140698; de los resultados del proyecto Anillo Soc 1109, "Relaciones transfronterizas entre Bolivia y Chile: paradiplomacia y prácticas sociales 1904-2004" financiado por CONICYT, llevado a cabo por el Instituto de Estudios Internacionales de la Universidad Arturo Prat; y de los resultados del proyecto FONDECYT Postdoctorado 3180173, "Itinerarios terapéuticos transfronterizos".

\section{Referencias citadas}

Albó, X. (1988). ¡Ofadifá Ofadifá! Un Pentecostés chiriguano. En Guerrero, B. (Ed.). De Indio a Hermano, Pentecostalismo indigena en América Latina (pp. 231-328). Iquique: Ediciones CAMPVS.

Albó, X. (2003). Aymaras entre Bolivia y Chile. En Morin, F. y Santana, R. (Ed.). Lo transnacional. Instrumento y desafio para los pueblos indígenas (pp. 85-146). Quito: Abya-Yala.

Barth, F. (2000). Boundaries and connections. En Cohen, A. F. (Ed.). Signifying Identities. Anthropological perspectives on boundaries and contested values. Londres: Routledge.

Bartolomé, M. (2008). Fronteras estatales y fronteras étnicas en América Latina. Notas sobre el espacio, la temporalidad 
y el pensamiento de la diferencia. En Velasco, L. (Coord.). Migración, fronteras e identidades étnicas trasnacionales (pp. 35-77). México, DF: El Colegio de la Frontera Norte.

Botero, L. (2008). Los Awá y sus "relaciones religiosas fronterizas". Indiana, 25, 9-25.

Brenna, J. (2011). La mitología Fronteriza: Turner y la Modernidad. Estudios Fronterizos, Nueva época, 12(24).

Del Cairo, C. (2003). Construcciones culturales de la identidad en una frontera de colonización amazónica. En García, C. (Ed.). Fronteras. Territorios y metáforas (pp. 103-119). Medellín: Hombre Nuevo Editores - Instituto de Estudios Regionales.

D'Epinay, C. (1968). El refugio de las masas: estudio sociológico del Protestantismo Chileno. Santiago: Editorial del Pacífico.

Eliade, M. (1981). Lo sagrado y lo profano (4ª edición). Buenos Aires: Editorial Guadarrama/Omega.

Garcés, A., Moraga, J. y Maureira, M. (2016). Tres movilidades para una ruta: Espacio, comercio y transnacionalidad boliviana en Tarapacá. Estudios atacameños. Arqueología y Antropología Surandinas, 53, 205-220.

Giménez, G. (2000). Territorio, cultura e identidades: la región socio-cultural. En Rosales, R. (Coord.), Globalización y regiones en México (pp. 19-33). México: UNAM, Facultad de Ciencias Políticas y Sociales - Porrúa.

González, H. (1998a). La posición de aymaras chilenos y bolivianos en la estructura de tenencias de la tierra en los valles de Lluta y Azapa. Arica: TEA.

González, H. (1998b). Características de la inserción de aymaras chilenos y bolivianos en el área de Arica. Serie de Documentos de Trabajo. Arica: TEA.

Grimson, A. (2003). Introducción. En Michaelsen, S. y Jonson, E. (Comps.). Teoría de la Frontera. Los límites de la politica cultural. Madrid: Gedisa.

Londońo, J. (2003). La frontera, un concepto en construcción. En García, C. (Ed.). Fronteras. Territorios y metáforas (pp. 61-83). Medellín: Hombre Nuevo Editores - Instituto de Estudios Regionales.

Mansilla, M. (2014). La cruz y la esperanza. La cultura del pentecostalismo chileno en la primera mitad del siglo XX. México, DF: MANDA - UNAM - UNAP.
Mansilla, M. (2016). La buena muerte. La cultura del morir en el Pentecostalismo. Santiago: UNAP - RIL.

Mansilla, M. Á., Muñoz, W. y Orellana, L. (2014). Los dilemas comunitarios y étnicos y religiosos: las investigaciones antropológicas del pentecostalismo aymara y mapuche en Chile (1967-2012). Estudios atacameños. Arqueología y Antropologia Surandinas, 49, 153-175.

Mansilla, M. y Muñoz, W. (2017). ¿Evangélicos o aymaras?: dinámicas de las representaciones culturales de los evangélicos aymaras (Chile). Estudios Atacameños. Arqueología y Antropología Surandinas, 54, 239-258. Mansilla M. y Muñoz, W. (2017). La dramatización de la cultura: los procesos de conversión evangélica aymara (Chile). Chungara. Revista de Antropología Chilena, 49(2), 241-250.

Moulián, R. (2018). El sello del Espíritu derramado sobre la carne. Retórica de la presencia, mediaciones rituales y enacción del Espiritu Santo en el culto pentecostal. Valdivia: Kultrún.

Nolasco, M., Molina, V., Acevedo, M. L., Roldán, I., Bravo, B. y Merino, S. (1992). Breviario de los Municipios Fronterizos de México. México, DF: Paraná, S.A. - Centro de Ecodesarrollo - Centro Nacional de Desarrollo Municipal.

Núñez, A., Arenas, F. y Sabatini, F. (2013). Producción de fronteras e imaginarios geográficos: de la nacionalización a la globalización de la cordillera de Los Andes. Chile, siglos XX y XXI. En Fronteras en movimiento e imaginarios geográficos. La cordillera de Los Andes como espacialidad sociocultural. Santiago: Instituto de Geografía UC y RIL.

Orellana, L. (2008). El Fuego y la Nieve: Historia del Movimiento Pentecostal en Chile, 1909 - 1932. Concepción: CEEP-Ediciones.

Paniagua, L. (2002). La palabra como frontera simbólica. Revista de ciencias sociales, 1-2(111-112), 143-154.

Rivera, C. (2014). Creencias divergentes en territorios comunes. Religiosidades en la frontera Guatemala-México. Boletín Americanista, 2(69), 97-108.

Rivière, G. (1988). Cambios sociales y pentecostalismo en una comunidad Aymara. Revista Fe y Pueblo, 3, 24-30.

Rivière, G. (2004). Bolivia: el pentecostalismo en la sociedad aimara del Altiplano. En A. Spedding (Comp.), Gracias a Dios y a los Achachilas. Ensayos la sociología de la religión en los Andes (pp. 259-294). La Paz: ISEAT - PLURAL. 
Solís, D. y Martínez, C. (2012). Construcción de fronteras simbólicas y prácticas religiosas. Estudios fronterizos, 13(25), 9-30.

Ströbele-Gregor, J. (1989). Indios de piel blanca. Evangelistas fundamentalistas en Chuquiyawu. La Paz: Hisbol.

Tapia, M. (2012). Frontera y migración en el norte a partir del análisis de los censos de población: Siglos XIX-XXI. Revista de Geografía Norte Grande, 53, 177-198.

Tapia, M. (2015). Frontera, movilidad y circulación reciente de peruanos y bolivianos en el norte de Chile. Estudios Atacameños. Arqueología y Antropología Surandinas, 50, 195-213.

Tapia, M. y González, A. (2014). Regiones fronterizas: migración y los desafios para los Estados nacionales latinoamericanos. Santiago: RIL.

Tapia, M., Liberona, N. y Contreras, Y. (2017). El surgimiento de un territorio circulatorio en la frontera chileno-peruana: estudio de las prácticas socio-espaciales fronterizas. Revista de Geografía Norte Grande, 66, 117-141.

Wagner, P. (1970). The Protestant Movement in Bolivia. California: William Carey Library.

\section{Revista Fuego de Pentecostés}

Avance de la obra en Calama (2000). Fuego de Pentecostés, $849,18$.

Bolivia para Cristo (1980). Fuego de Pentecostés, 616, 12-13.

Consagración de dos nuevos templos de la Iglesia en Villa Pagador, Bolivia (1994). Fuego de Pentecostés, 777, 13.

Consagración de Templos Centrales en Bolivia. Huanuni (1998). Fuego de Pentecostés, 827, 16.

Consagración de tres locales de predicación de la iglesia de Oruro, Bolivia. Locales: Vinto-Toledo-y Ankola (1985). Fuego de Pentecostés, 665, 10-11.

Consagración del Nuevo templo en San José de Kala - Bolivia (2005). Fuego de Pentecostés, 915, 17.
Consagración del Templo en San José de Kala. Iglesia en Huachacalla, República de Bolivia (1989). Fuego de Pentecostés, 773, 18.

Consagración del Templo en Todo Santo - La Rivera (2004). Fuego de Pentecostés, 902, 21.

Historia de la Iglesia Evangélica pentecostal en Bolivia (1993). Fuego de Pentecostés, 763, 12-13.

Huellas de un misionero pentecostal en Bolivia (1985). Fuego de Pentecostés, 671, 5-8.

Inauguración de un nuevo templo de la Iglesia en Caranavi La Paz - Bolivia (1997). Fuego de Pentecostés, 819, 10.

Jehová guarda (1985). Fuego de Pentecostés, 668, 12.

La fiesta de la Ch'Alla. ¿Tras la prosperidad y el bienestar? (2005). Fuego de Pentecostés, 906, 9.

Mis agradecimientos al Dios Todopoderoso (1989). Fuego de Pentecostés, 723, 12.

Misión a la amada Bolivia (1985). Fuego de Pentecostés, 672, 11.

Misión de jóvenes Bolivianos al Perú y Chile (1990). Fuego de Pentecostés, 724, 15.

Misión de jóvenes de la iglesia de Sargento Aldea a la hermana República de Bolivia (1985). Fuego de Pentecostés, 673, 7.

Noticias de la iglesia en Bolivia consagración de cuatro templos (1987). Fuego de Pentecostés, 697, 18.

Noticias de la obra del Señor en la Región Yungueñas (1996). Fuego de Pentecostés, 808, 12.

Primer grupo de ciclistas de la Iglesia en Villa Tunari-Bolivia (2003). Fuego de Pentecostés, 883, 15.

Reseńa de estudio bíblico internacional de pastores realizado en Oruro-Bolivia (1994). Fuego de Pentecostés, 779, 6-7.

Reseña de la Conferencia Internacional de Pastores en Challapata, República de Bolivia (1997). Fuego de Pentecostés, $816,7$.

Viaje Misionero al sur de Bolivia (1988). Fuego de Pentecostés, 701,10 . 